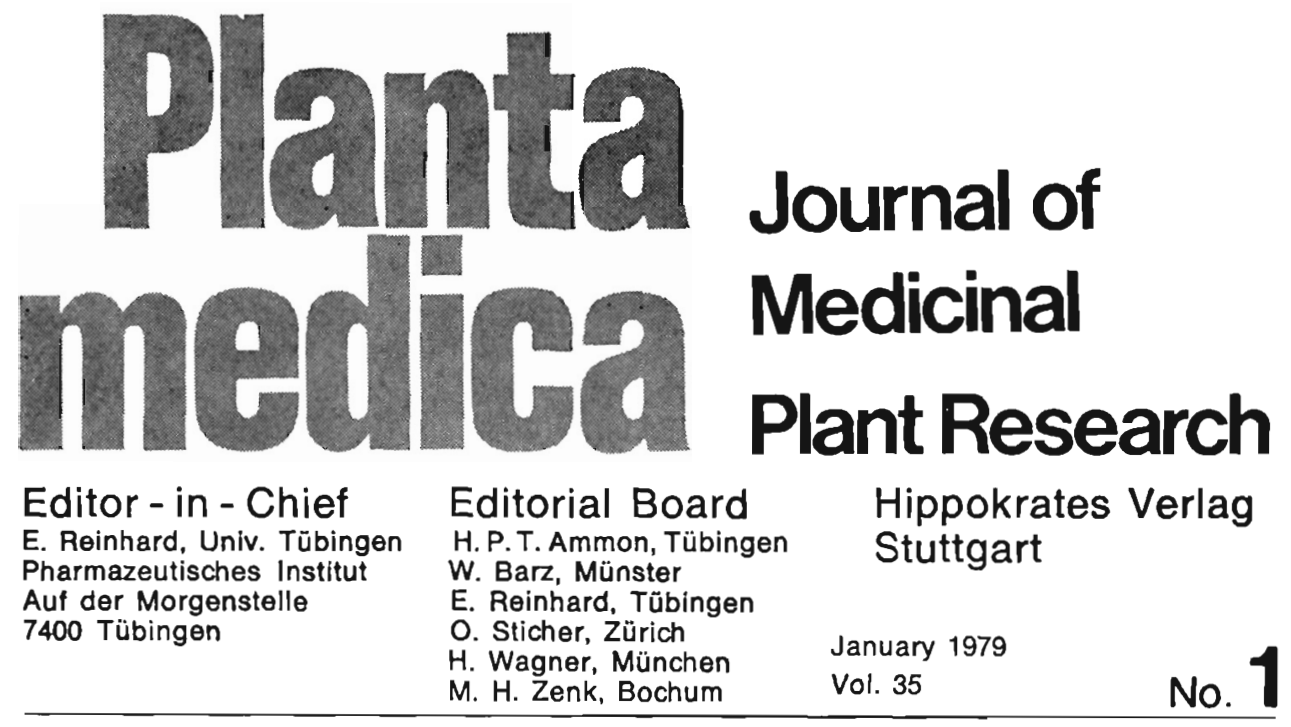

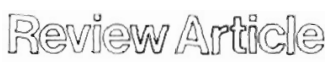

\title{
Antibiotic Polypeptides - Biosynthesis on Multifunctional Protein Templates
}

Horst Kleinkauf

Max-Volmer-Institut für Physikalische Chemie und Molekularbiologie, Abtl. Biochemie, Berlin.

Key Word Index: Antibiotic polypeptides; Non-Ribosomal Biosynthesis of Peptides; Multifunctional Protein Templates; 4'-Phosphopantetheine; Amino Acid Activation; Initiation; Elongation; Transfer and Termination in the Enzymatic Biosynthesis of Peptides; Substrate Analogues; Gramicidin S; Structure and Function of Peptide Antibiotics; Growth Conditions of Microorganisms Producing Peptide Antibiotics; Preparative Biosynthesis of Peptides.

Since the discovery of antibiotics a few hundred peptide antibiotics have been described in the literature. These substances are formed by a number of microorganisms and contain one or several amino acids or amino acid derivatives.
167 different antibiotics which are mainly polypeptides have been described alone from the organism Bacillus [1].

Structure of peptide antibiotics

The characteristics of the primary 
structure which have been found for the whole class of peptide antibiotics and which are especially interesting from a biochemical view point and also represent a difference from proteins are the following:

1. A low molecular weight compared to long chain peptides of the protein class. The molecular weight of the peptide antibiotics lies between 270 (bacilysin) and 4500 (licheniformin). Most of the peptide antibiotics have a molecular weight ranging from 1100 to 1400.

2. The occurence of unusual residues, including $\mathrm{D}$-amino acids and other amino acids not normally found in proteins like ornithine (gramicidin S), amino-iso-butyric acid (alamethicin), hydroxy acids (valinomycin), fatty acids (polymyxin), chromophore (actinomycin), spermidine (edeine A) and others.

3. The occurence of cyclic structures and modifications of the terminal part of the chain.

4. The frequency of substitutions of single specific amino acids by their analogues. These substitutions are partially dependent on changes of amino acid concentration in the environment of the microorganism.

5. Peptide antibiotics are normally resistent to hydrolysis by peptidases because of their cyclic structure or because of the unusual amino acids or substituents at the amino or carboxyl end in the case of the linear chains.

\section{Speculations about functions of peptide antibiotics}

There has been speculation about the function of peptide antibiotics in the cell cycle. One of the functions might be the killing or inhibition of growth of other microorganisms - these could be bacteria as well as protozoa which are used as food by bacteria - in the struggle for better growth conditions of the peptide forming bacteria. I do not want to discuss all the hypotheses which deal with the overproduction and further utilization of amino acids and the excretion of waste products. All these hypotheses lack valid proof.

The chemical difference between peptide antibiotics most probably indicates different intracellular functions. One assumes that bacitracin increases the uptake of various two-valent metal ions. The function of the bacitracin peptide might therefore lie in the stimulation of the uptake of essential divalent cations from the cell surface and transfer to the transport mechanism in the cytoplasma $[2,3]$.

Furthermore, it is interesting to consider the possibility that antibiotics - as bacterial equivalents to the hormones in the regulation of cell differentiation could function e.g. in the transformation of the vegetative cell to spores. During the last years a number of publications have appeared in which a generegulating role of these peptides has been described. Some of these peptides form complexes with DNA while others react with subunits of RNA polymerase [4]. Sarkar and Paulus [5] assume that tyrocidine controls RNA synthesis during the early stage of sporulation by selective inhibition of transcription of those genes which function during the vegetative growth phase. It has been shown that the inhibition of RNA synthesis by tyrocidine occurs at the same 
time as formation of DNA-tyrocidinecomplexes [6]. The total inhibition of transcription of DNA by tyrocidine is reversed - at least partially - by the linear gramicidins by a still unknown mechanism $[7,-8]$. Paulus and Sarkar [9] suggest that this partial inhibition is caused by a specific regulatory activity of gramicidin. It has been shown that gramicidin inhibits the formation of stable complexes between RNA polymerase and DNA to the same extent as it inhibits total RNA synthesis. These observations might indicate that gramicidin influences the formation of the RNA-polymerase-DNA-complex and therefore prevents RNA synthesis. In addition, it has been shown that transcription of certain types of bacterial genes which are relatively insensitive to actinomycin $\mathrm{D}$, show a total resistence to gramicidin. This indicates that gramicidin has a strong effect on RNA synthesis and might function in the control of transcription [10].

The production of the peptide antibiotics normally starts in the late logarithmic growth phase and stops earlier or later during the sporulation phase dependent on the organism. Many examples are known of genetic and physiological correlation between formation of antibiotics and formation of spores. E. g., inhibitors of sporulation also inhibit antibiotic synthesis [11]. Both are inhibited by glucose [12]. Furthermore, the early phase of sporulation correlates with the synthesis of antibiotics [13]. LEE et al. [14] have shown that the synthesis of tyrocidine by Bacillus brevis coincides with the early phase of sporulation. The production of tyrocidine is transferred from the soluble cell fraction to the pre-spore membrane.

Gramicidin $S$ located in the spores is degraded by intracellular proteases during germination [15]. Gramicidin S has been shown to be adsorbed on the surface of the cells and to be partially removed by several washings with TrisHCl-buffer [16]. Experiments by SCHAZSCHNEIDER [17] with B. brevis ATCC 8185 indicated that after washing of the spores with $70 \%$ ethanol the germination proceeded faster than with untreated spores and an increase in germination was observed. Normally "asporogony" is correlated with the absence of antibiotics in the cell.

On the other hand, there are a number of observations which show that sporulation can be uncoupled from the formation of antibiotics. In these cases either antibiotics are formed and no spores or vice versa [18]. In this connection, the interesting experiments by KAMBE et al. [19] show that mutants which are defective in the production of antibiotics can nevertheless form spores. The same is true for a mutant of Bacillus licheniformis which cannot synthesize bacitracin but sporulates in a normal way [20].

These above mentioned experiments indicate that the function of antibiotics in the cell is still unclear. The hypothesis that sporulation and antibiotics formation are regulated by similar or possibly by the same factors but otherwise are independent of each other, seems to explain best the known facts.

Conditions for growth and biosynthesis of the microorganism producing peptide antibiotics.

The culture conditions which favor 
antibiotic formation or the formation of the corresponding synthetase are, of course, of interest in this connection. It has been observed for many bacteria and molds that the synthesis of compounds of unknown metabolic function starts after the period of growth. This period of antibiotics formation is called "idiophase" (secondary metabolism) while the period of growth is called "trophophase". Biochemically the trophophase can also be referred to as primary metabolism. The secondary metabolites include compounds like antibiotics, toxins etc.

The starting point of the idiophase can be defined in many cases as the time when the carbon sources in the media are exhausted [22]. If during the experimental examination of the formation of the secondary metabolites the carbon source is changed from an easy-to-utili$z e$ one to a more difficult-to-utilize one a different pattern of total metabolism is observed for the organism. During the growth of Fusarium sambucinum in a lactose medium the formation of the depsipeptide enniatin starts earlier than wher the cells are grown on a glucose containing medium [23]. When the latter medium is used the synthesis of the antibiotic starts only when the glucose is almost completely utilized. Similar results have been obtained for penicillin formation when a lactose containing medium was used [24]. In these two cases the synthesis of the antibiotic starts already during growth.

The repression by glucose is a well known phenomenon and has been shown for products such as gibberellic acid, chloramphenicol, streptomycin, siomycin and actinomycin [25]. The ques- tion which medium is the right one for antibiotic production by a certain organism, is dependent on the problems connected with the growth. If high yields of certain secondary metabolites are desired the selection of the carbon source is dependent on price and degree of utilization and on the effectiveness of incorporation into the products during the fermentation.

The enzymologist is primarily interested in obtaining highly active enzyme in high yields from the cell. The yield of the secondary metabolite is only of minor importance. In analogy, for the investigation of the biogenesis a very active cell material is preferred over a highly productive material that has low enzyme activity. Examples are the syntesis of enniatin B by Fusarium oxysporum or of alamethicin by Trichoderma viride. In the case of enniatin, yields of $1-2 \mathrm{~g} / \mathrm{l}$ are obtained when the cells are grown in a medium containing high concentrations of lactose. On the other hand, when these cells are broken, only little enzyme activity is observed and the enzymes are relatively unstable. When grown on a minimal medium, e. g. NRRL sporulation medium, only a low yield of enniatin is observed but very active and stable enzyme preparations are obtained. The same effect has been demonstrated for alamethicin. Here the use of the Upjohn-medium [26] results in high alamethicin yields and low and unstable enzyme activity. When the NRRL sporulation medium is used opposite results are obtained. Likewise, it is recommended to use minimal media with a difficult-to-utilize carbon source for the growth of Streptomycetes. If treated in this way 
(growth on a chemical defined medium) Streptomyces tsusimaensis or Streptomyces antibioticus will produce highly active mycelia for formation of valinomycin or actinomycin. It is interesting to note that the production of valinomycin starts already after a few hours. For Streptomyces antibioticus, the formation of actinomycin can be observed over the end of the growth phase (2 days) up to the tenth day. However, this effect is only observed when galactose, lactose or similar difficult-to-utilize sugars are used as carbon source. When glucose is applied very little actinomycin is formed and the activity of the cells is low. An examination of the medium indicated that the glucose was completely used up after 5 days while in the case of the galactose medium even after 10 days $30-40 \%$ of the galactose was found remaining in the medium. It should be mentioned here that glucose is a catabolic repressor of the synthesis of actinomycin [27]. Experiments concerning the synthesis of actinomycin in Streptomyces parvulus have shown that fructose is the best carbon source for the synthesis of the antibiotic in so far as yield and efficiency of synthesis are concerned. In this case only $30 \%$ of the sugar has been utilized during fermentation [28]. It is interesting to note that fructose also is a good carbon source for the synthesis of gramicidin $\mathrm{S}$ in Bacillus brevis [29]. Glutamate is a good source of nitrogen for such fermentations. Glutamate is normally most suitable as the only nitrogen source for Streptomycetes. This compound has also been proven very helpful as a source of nitrogen and carbon for the synthesis of bacitracin in Bacillus licheniformis
[30]. An inhibition by glucose has also been found in this organism. This inhibition might result from acids like pyruvic acid or acetic acid which are formed during glucose metabolism.

Histidine has positive effects on the formation of antibiotics in some cases. Supplementation of a glutamate medium with histidine shows a good stimulation of the synthesis of actinomycin in Streptomyces parvulus. There also is a clear connection of the histidine content of the medium and streptomycin synthesis in Streptomyces griseus [31].

Tryptophan at concentrations above $5 \times 10^{-3} \mathrm{M}$ is a strong inhibitor of the synthesis of actinomycin despite the fact that tryptophan is a precursor of the chromophore of actinomycin. Most likely this is due to a competitive inhibition of the synthetic process. It is therefore favorable to grow the organism in the chemical defined medium (glutamate-galactose-mineral salts me-) dium) instead of a complex medium.

\section{Biosynthesis of peptide antibiotics}

The biosynthesis of antibiotics is different from protein biosynthesis. $\mathrm{MACH}$ [32] suggested a biosynthetic pathway for the formation of tyrocidine based on in vivo experiments which have shown that puromycin, chloramphenicol and aureomycin do not prevent the incorporation of labelled amino acids into tyrocidine. The synthesizing system was also insensitive to DNase and RNase. The formation of D-Phe-L-Pro-diketopiperazine which was assumed to be the first peptide forming reaction in the synthesis of gramicidin $\mathrm{S}$, was not affected by nucleases, chloramphenicol or mitomycin C $[33,34]$. 
During the last years a great number of biosynthetic mechanisms for peptides have been under investigation. It was possible to show for several peptide antibiotics that they are synthesized by a nucleic acid free mechanism. This is true for gramicidin S, tyrocidines, linear gramicidins, bacitracins, edeines, mycobacillins, malformins, polymyxins, colistins, cephalosporins, penicillins, alamethicins, enniatins, valinomycin, actinomycins and echinomycins.

Our present knowledge of the nonribosomal biosynthesis of peptide antibiotics is mainly based on results from experiments concerning biosynthetic mechanisms of gramicidin S (Fig. 1) and tyrocidines $[35,40]$.

These decapeptide antibiotics are synthesized by Bacillus brevis, culture number ATCC 9999 or ATCC 8185. During these experiments a new type of peptide bond formation was found which is called the protein-thiol-template-mechanism. The biosynthetic mechanism of these peptides proceeds with the involvement of the thiol groups of the enzyme. These thiol groups stabilize the activated amino acids. In addition, a 4'-phosphopantetheine takes part in the transfer of peptides to achieve a condensation of the peptide with the next thiolester-activated amino acid residue.

The synthesis of a number of other peptide antibiotics seems to be similar to the biosynthetic mechanism of gramicidin $S$ and the tyrocidines. The longest peptide synthesized by this mechanism in vitro is alamethicin which is a nonadecapeptide [41]. Experiments with mutants have indicated that the size of the peptides which can be synthesized in this way, is about 30-35 amino acids.

Zharikova et al. [42] have shown that mutants of Bacillus brevis can synthesize longer peptides in place of gramicidin S, e.g. esein with 29 amino acids or graceulin with 34 amino acids.

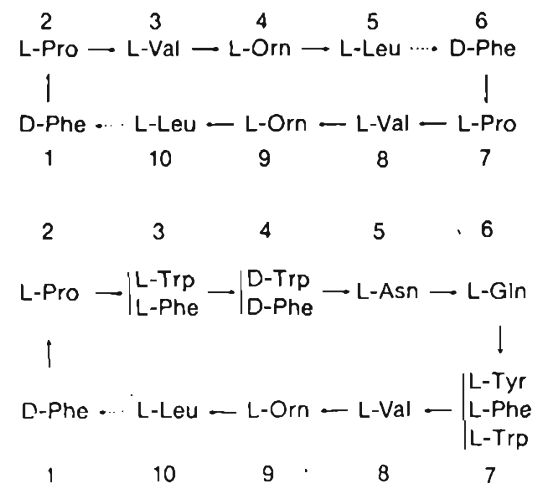

gramicidin $\mathbf{S}$

tyrocidines

Fig. 1. Structures of gramicidin $S$ and tyrocidines. Polymerization is in the direction of the solid arrows from $\mathrm{N}$-terminal $\mathrm{D}$-phenylalanine to L-leucine. Cyclization in gramicidin $\mathrm{S}$ bio- synthesis occurs between two identical pentapeptides, D-Phe ${ }_{1} \rightarrow{\mathrm{L}-\mathrm{Leu}_{5} \text { and D-Phe }}_{6} \rightarrow \mathrm{L}$ $\mathrm{Leu}_{10}$. Linkage occurs at the dotted arrows. 
Both contain ornithine in their structure. Nothing is known about the configuration of the amino acids.

Synthetases of gramicidin $S$ and the tyrocidines (Fig. 2) have been separated into two or three complementary enzymes $[43,44]$. Their substrate amino acids are activated as amino acyl adenylates in the first step (Fig. 3 ) in analogy to the amino acyl-tRNA-synthetases in protein biosynthesis [45]. Amino acyl adenylates which are not covalently bound, are transferred to thiol groups in contrast to hydroxy groups as in the case of tRNA [46].

The transport of the growing peptide chain from one thiolester-activated

\begin{tabular}{|c|c|c|c|c|}
\hline Product & Enryme & Mol.WT & PAN & $\begin{array}{r}\text { No. of A } \\
\text { Act }\end{array}$ \\
\hline Gramicidin S & $\begin{array}{l}\text { GS } 1 \\
\text { GS } 2\end{array}$ & $\begin{array}{l}100.000 \\
280.000\end{array}$ & 1 & \\
\hline Tyrocidine & $\begin{array}{ll}\text { TY } & 1 \\
\text { TY } & 2 \\
\text { TY } & 3\end{array}$ & $\begin{array}{l}100.000 \\
230.000 \\
440.000\end{array}$ & $\begin{array}{l}1 \\
1\end{array}$ & \\
\hline Bacitracin & $\begin{array}{ll}\text { BA } 1 \\
\text { BA } 2 \\
\text { BA } 3\end{array}$ & $\begin{array}{l}200.000 \\
210.000 \\
380.000\end{array}$ & $\begin{array}{l}1.3 \\
0.6 \\
1.3\end{array}$ & \\
\hline Edeıne & $\begin{array}{ll}\text { ED } & 1 \\
\text { ED } & 2\end{array}$ & $\begin{array}{l}210.000 \\
180.000\end{array}$ & . & \\
\hline Gramicidin & $\begin{array}{l}\text { LG } 1 \\
\text { LG } 2 \\
\text { LG } X\end{array}$ & $\begin{array}{l}160.000 \\
350.000 \\
\text { n. d }\end{array}$ & $\begin{array}{l}1 \\
1 \\
n\end{array}$ & \\
\hline Alamethicin & $A L X$ & 480.000 & $n d$ & \\
\hline
\end{tabular}

Fig. 2 Features of multienzyme systems producing peptides. PAN: moles of 4'-phosphopantetheine/mol enzyme. Enzymes are numbered in correspondence with their catalytic function in the peptide elongation.

\section{$E_{s H}+\mathbf{A T P}+\mathbf{A A}$}
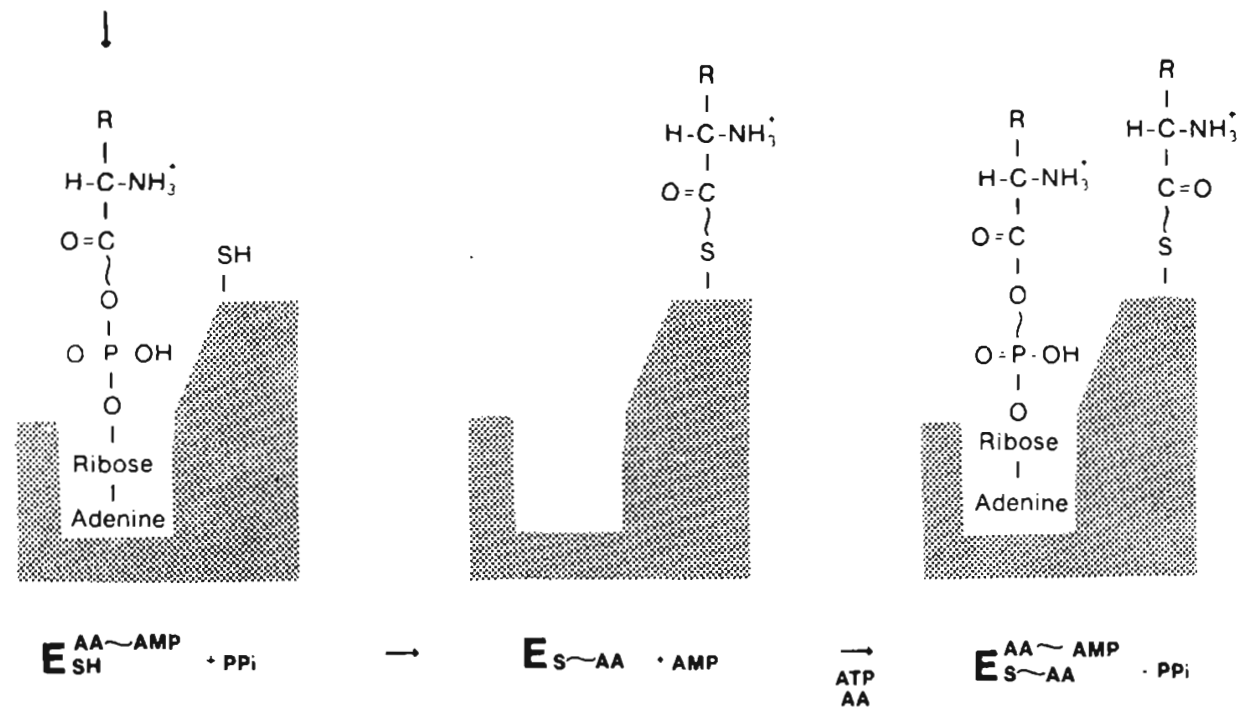

Fig. 3. Scheme of activation of amino acids by gramicidin $S$ synthetase. Amino acyl adenylate is formed by cleavage of pyrophosphate from ATP and transferred to a specific thiol group.
Formation of a second adenylate leads to an enzyme containing two moles of each amino acid in an activated state. 
amino acid to the next one occurs elongation, transfer and termination through transthiolation (Fig. 4) on a 4'- [49].

phosphopantetheine arm [47, 48]. The The reaction of initiation (Fig. 5) formation of peptide bonds proceeds will be discussed with the gramicidin $S$ via the four reaction types: initiation, synthetase as an example. Thiolester
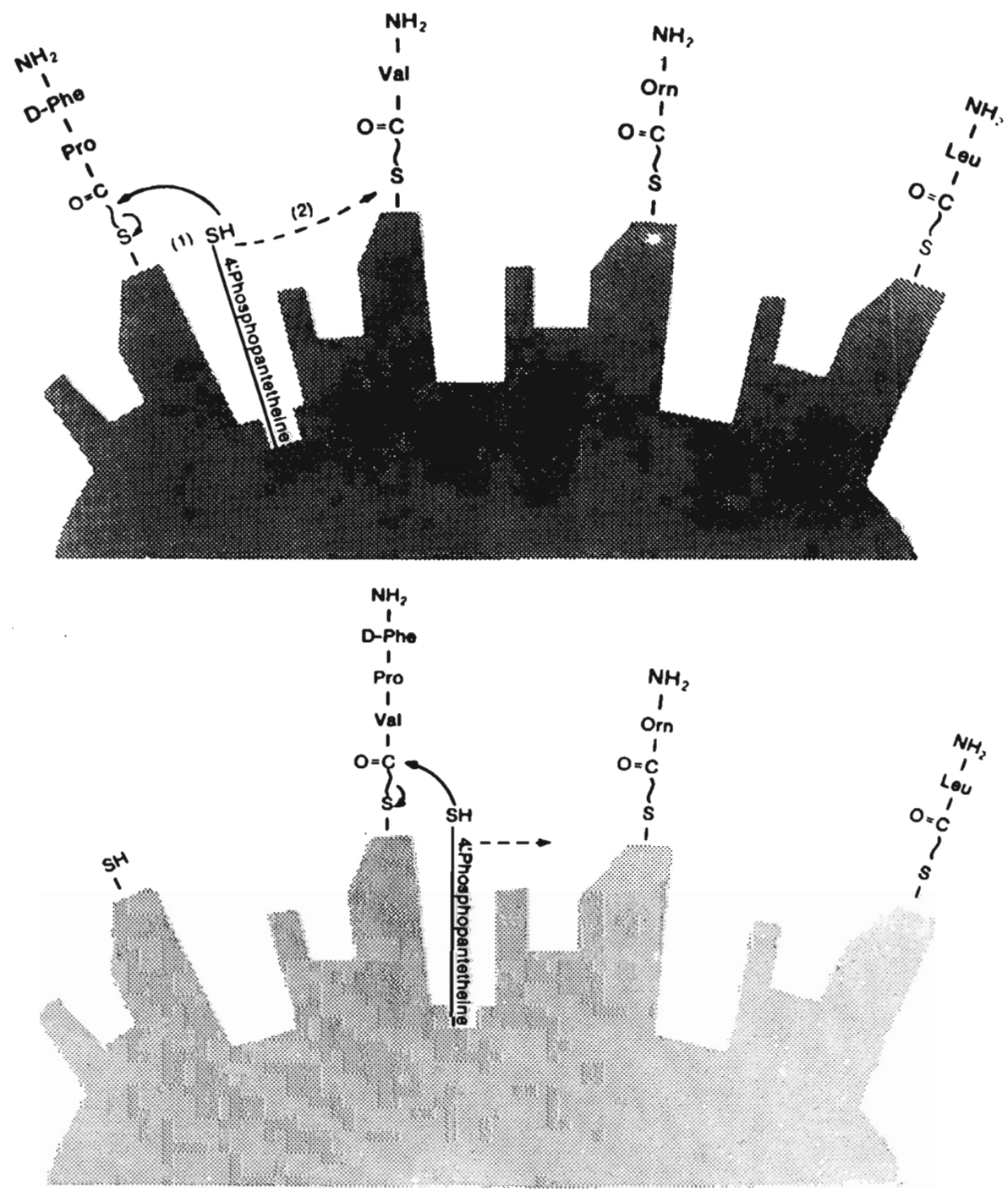

Fig. 4. Scheme of 4'-phosphopantetheine (PAN) mediated elongation in gramicidin $\mathrm{S}$ biosynthesis.

Top: The activated dipeptide D-Phe-Pro, located on a specific thiol, is accepted by PAN in a transthiolation reaction (1) and transported
(2) to the next activated amino acid valine where transpeptidation occurs.

Bottom: The activated tripeptide D-Phe-ProVal again undergoes transthiolation (1) and transpeptidation at the ornithine-binding site. 


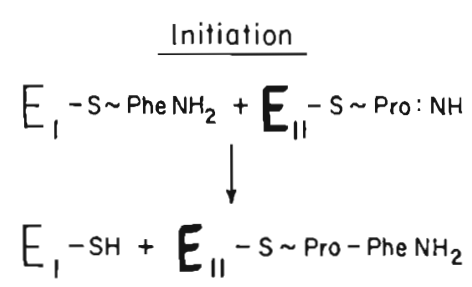

Fig. 5. Initiation reaction for biosynthesis of gramicidin $\mathrm{S}$ and the tyrocidines.

bound D-phenylalanine is transferred from the initiating multienzyme gramicidin $\mathrm{S}$ synthetase 1 (GS 1) to the thiolester bound L-proline on the multienzyme gramicidin $S$ synthetase 2 (GS 2).

Since the nomenclature of these enzymes - used in the past - led to confusion, we have numbered the enzymes in correspondence with their catalytic function in the elongation [35]. The initiation only occurs after proline has been bound [50]. LALAND's group [52] could show that in the gramicidin $\mathrm{S}$ synthetase the thiolester bound D-phenylalanine group on the gramicidin $S$ synthetase 1 is not directly transferred to the imino group of proline but is first covalently bound by a specific acceptor group on the gramicidin $S$ synthetase 2 .

This transfer is dependent on the binding of the proline to the gramicidin $S$ synthetase. It is assumed that the binding of proline to this enzyme results in a conformational change which is required for the transfer. The proline activation center as well as the transfer site for phenylalanine on the gramicidin $S$ synthetase 2 are the control centers of this multienzyme.

VATER et al. [53] could show that there is an increase of the thiolester incorporation into thiolester of the three other substrate amino acids of the heavy enzyme, when proline binds to the gramicidin $\mathrm{S}$ synthetase 2 . These effects are still increased, when phenylalanine is transferred to gramicidin $\mathrm{S}$ synthetase 2. They are most likely due to conformational changes of the multienzyme, resulting in an exposure of additional reaction centers induced by proline. In this way the efficiency of the gramicidin $S$ biosynthesis can be regulated. This mechanism is most likely of importance in the bacterial cell to obtain high gramicidin $S$ yields under conditions of limiting substrate concentrations.

In the elongation reaction the thiol bound peptide is transferred to a thiol bound amino acid [50,51]. This transfer occurs on the $4^{\prime}$-phosphopantetheine to which the peptide is linked by transthiolation. The peptide is then transferred to the next thiolester-activated amino acid. All thiol groups have to be accessible by the cofactor pantetheine. This results in a limitation of the size of the pantetheine-containing multienzyme complex. The multienzymes gramicidin $S$ synthetase 1 and 2 catalyze at least 18 reactions (Fig. 6). These can be divided into the following reaction types:

1. activation reactions which lead to adenylates after binding of amino acids and AT'P,

2. amino acylation of specific thiol groups,

3. formation of peptide bonds,

4. transthiolation of the peptide to the thiol group of pantetheine,

5. initiation reactions,

6. termination reactions.

The spatial organisation of so many active centers requires that the reactions of amino acylation and thiolester acti- 


\begin{tabular}{|c|c|c|c|}
\hline \multirow{2}{*}{\multicolumn{2}{|c|}{ (1) $E_{1}+L-P h \theta+A T P$}} & & \multirow[b]{2}{*}{$E_{1}(L-P h e-A M P)+P P$} \\
\hline & & $\rightleftarrows$ & \\
\hline (2) & $E_{1}$ (L-Phe-AMP) & $\longrightarrow$ & $E_{1}-S-L-P h e+A M P$ \\
\hline (3) & $E_{1}-S-L-P h e$ & & $E_{1}-$ S-D-Phe \\
\hline (4) & $E_{2}+\operatorname{Pro}+$ ATP & $\rightleftarrows$ & $E_{2}$ (Pro-AMP) + PP \\
\hline (5) & $E_{2}$ (Pro-AMP) & & $E_{2}-S-P r o+A M P$ \\
\hline (6) & $E_{1}-$ S-D-Phe $+E_{2}-$ S-Pro & & $E_{2}<\underset{X-D-\text { Pne }}{\text { S.Pro }}+E_{1}$ \\
\hline (7) & $E_{2}<$ S-Pro & & E $_{2}$-S-Pro-D-Phe \\
\hline (8) & $\mathrm{E}_{2}+\mathrm{Val}+\mathrm{ATP}$ & & $E_{2}(\mathrm{Val}-\mathrm{AMP})+P P$ \\
\hline (9) & $E_{2}$ (Val-AMP) & & $E_{2}-S-V a l+A M P$ \\
\hline (10) & $E_{2}+$ Orn + ATP & & $E_{2}(O r n-A M P)+P P$ \\
\hline (11) & $E_{2}($ Orn-AMP) & & $E_{2}-S-O r n+A M P$ \\
\hline (12) & $E_{2}+$ Leu + ATP & & $E_{2}$ (Leu-AMP) + PP \\
\hline (13) & $E_{2}$ (LeU-AMP) & & $E_{2}$-S-Leu + AMP \\
\hline (14) & $E_{2}<$ S-Pro-D-rino & & $E_{2}-S-$ Val-Pro-D-Phe \\
\hline (15) & $E_{2}<\underset{\text { S-Tripeptid }}{\text { S-Orn }}$ & Sp & $\mathrm{E}_{2}$-S-Orn-l'al-Pro-D-Phe \\
\hline (16) & $E_{2}<\begin{array}{c}\text { S-Tetrapr ptid } \\
\text { S-Leu }\end{array}$ & Sp & $E_{2}-S-L e u-O r n-V a l-P r o-D-P h e$ \\
\hline$(17,18)$ & $2 E_{2}$-S-Fentapeptide & $\longrightarrow$ & $\begin{array}{c}\text { Cyclo-(D-Phe-Pro-Val-Orn-Leu) } \\
+2 E_{2}\end{array}$ \\
\hline
\end{tabular}

Fig. 6. Reactions on the multienzymes gramicidin S-synthetase 1 and $2 . \times=$ unknown ac-

ceptor, $S_{p}=$ thiol group of $4^{\prime}$-phosphopantetheine.

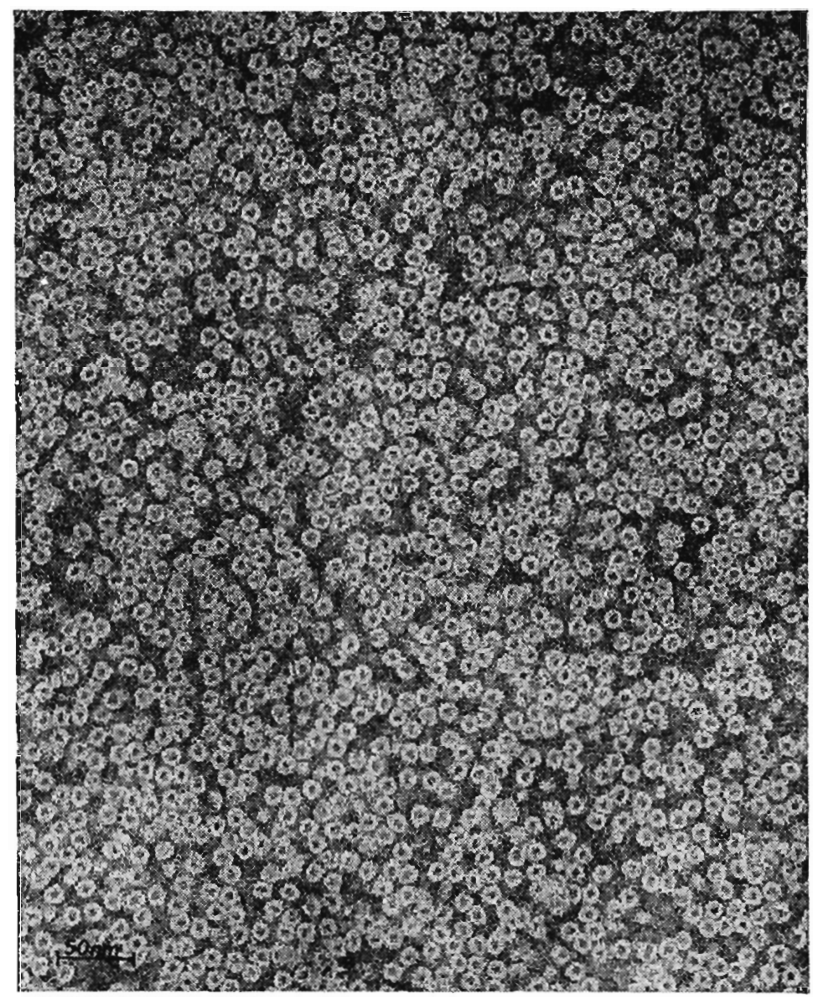

Fig. 7. Electron micrograph of purified gramicidin $S$ synthetase 2. Negative staining, uranylacetate $(\times 300.000)$ (Courtesy of J. WeCKE and P. GiesbrechT) 
vation have to be in adjacent positions and that the peptide formation and transthiolation reactions have to be localized at specific thiol groups.

Recently obtained electron micrographs of gramicidin $\mathrm{S}$ synthetase 2 (Fig. 7) show a "wheel “ structure of about $12 \mathrm{~nm} \phi$ [54]. The central part with high contrast has a diameter of about $4 \mathrm{~nm}$. Presumably, there is a connection with the rotating arm of the 4'-phosphopantetheine which has a length of $2 \mathrm{~nm}$. If the 4'-phosphopantetheine is positioned in the center it could reach all active centers located in the inner part of the circle [35]. KorschWITZ [55] has developed an enzyme model (Fig. 8) from these structure- function relations which is helpful in explaining experimental results and reaction processes. Adjacent to the amino acid recognition site, the transported donor peptide is recognized by every activating subunit and the reaction with the acceptor amino acid is catalyzed. This model indicates that the order of the amino acid activating enzymes is important for the sequence of the product, and in addition the chemical properties of the pantetheine bound intermediates as specific substrates also determine or control the sequence of the peptide.

LeE and LipmanN [56] favor another interpretation of the chain elongation. They consider the pantetheine-carrying

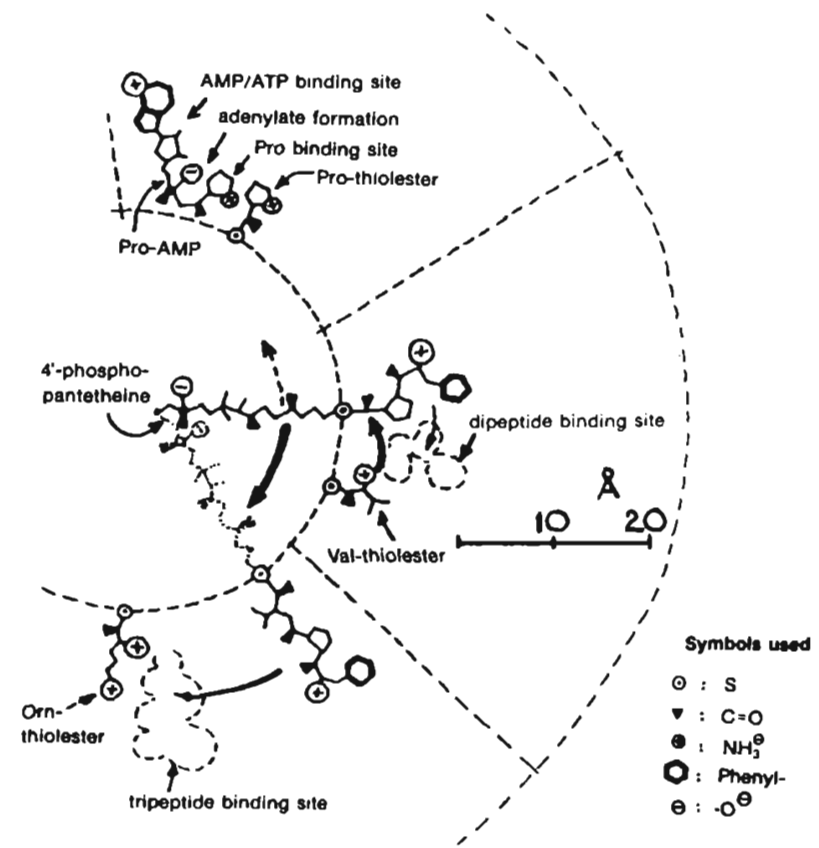

Fig. 8. Hypothetical scheme of transpeptidation and transthiolation of activated peptides on gramicidin S-synthetase. Dimensions as deduced from electron micrographs have been tentatively correlated with dimensions of substrates, intermediates and cofactor. Intermediate peptides are recognized (binding site) on each amino acid activating subunit before peptidation reaction occurs. 
protein complex as a peptidyl transferase and assume that the reaction site for the peptide formation is located on this subunit.

Experiments with the tyrocidine synthetase multienzymes show that they consist of subunits of about equal size of 70000 daltons [56,57]. The subunits are most likely located with their amino acid-specific reaction centers around a peptidyl carrier protein in the sequence of the product to be synthesized. According to the hypothesis of Lipmann's group, based on the number of active amino acids and their molecular weigths, one can assume that the amino acid-activating subunits of the peptide-synthesizing multienzyme have a molecular weight of 70000 daltons $[39,58,59]$.

In experiments with gramicidin $S$ synthetase 1 and 2, VATER [60] and Koischwitz [61] showed that the functional active enzymes could not be separated into subunits in contrary to the tyrocidine-synthetase (Fig. 9). These results have recently been confirmed by Christiansen et al. [62] for gramicidin S synthetase 2 .

Because of the structural similarities

(1) $1 \%$ SDS / $1 \%$ 2-Mercaptoethanol / 3' $100^{\circ} \mathrm{C}$ SDS-Page // SDS-Sucrose-Gradient

(2) $2 \%$ SDS / $0.2 \mathrm{M}$ Dithiothreitol / $60^{\prime} 95^{\circ} \mathrm{C}$ SDS-Page

(3) $6 \mathrm{M}$ Urea / Gelfiltration

(4) Sulfonation in $8 \mathrm{M}$ Urea (Chan, 1968)

(5) Carboxymethylation and Citraconylation in $4,5 \mathrm{M} \mathrm{GuOH} \cdot \mathrm{HCl}$,

$6 \mathrm{M}$ - Urea-Page (Engeser et al., 1977)

Fig. 9. Integrity of gramicidin S-synthetase 2 multienzyme. SDS = sodium dodecyl sulfate; PAGE = polyacrylamide gel electrophoresis; $\mathrm{Gu} \mathrm{OH}=$ guanidino.

Chan [77], Engeser [78]. of tyrccidine and gramicidin $\mathrm{S}$, one would have expected a corresponding analogy of the enzyme systems. The fact that they are not alike is not necessarily a contradiction because there is not sufficient information at the present time about the intracellular condition of these multienzymes or about their in vivo regulation.

With regard to the evolution of the process, it is assumed [39] that there is a fundamental relationship between the polypeptide and fatty acid biosynthesis, because both processes involve a polymerization of short, activated carboxyl compounds. Both reaction mechanisms show parallels. The product of the polypeptide synthesis grows by transpeptidation of thiolester-bound peptides to thiolester-bound amino acids. One has to assume, and there is also some evidence in favour [50], that the pantetheine catalyzes a translocation leading either to condensation or to transthiolation. This transport mechanism of the growing peptide chain resembles the mechanism of the growing fatty acid chain. In this system also multienzyme complexes with thiolgroups and 4'-phosphopantetheine are participating in the activation of the building blocks and in their transport lcading to the elongation of the fatty acid chain. An obvious difference between the two mechanisms is that in the fatty acid synthesis identical two-carbon-fragments $\left(\mathrm{CH}_{2}-\mathrm{CO} \sim\right)$ are bonded, whereas in peptide synthesis the required amino acids are selected and linked in the correct sequence.

In the transfer reaction a peptide is transferred to an activated amino acid on another multienzyme complex - as 
is shown in the case of tyrocidine where the peptide is transferred from the intermediate to the heavy enzyme fraction. It is unknown whether a specific acceptor group exists similar to the initiation reaction for gramicidin on the heavy enzyme or whether this transfer reaction proceeds in a similar fashion as the elongation reaction.

The termination reaction in which two pentapeptides react head-to-tail to form the cyclic gramicidin $S$, is not entirely understood. LipMANN's group suggested an intermolecular cyclization of the two pentapeptides yielding gramicidin S $[39,63]$, while LaLand's group is suggesting an intramolecular reaction and is postulating a waiting position for the pentapeptide on the gramicidin $S$ synthetase 2 [64]. SAXHOLM [65] speculates that the $\mathrm{D}$-leucine binding position on the gramicidin $\mathrm{S}$ synthetase 2 is identical with the waiting position for the pentapeptide. Kurahashi [37] however, pointed out that an experiment by Roskoski et al. [51] contradicts such a model. In this experiment it was shown that gramicidin $\mathrm{S}$ could be synthesized by gramicidin $S$ synthetase 1 and 2 both of which were previously charged with their substrate amino acids and freed of amino acyl adenylates. In this experiment no growing peptide was bound to gramicidin $S$ synthetase.

Experiments by Gevers et al. [46] have shown that pentapeptides can be demonstrated only after short incubation with leucine in an otherwise complete system. These pentapeptides are formed in small quantities - compared to other peptide intermediates. These experiments contradict an intramolecular cyclization. Basically, the possibility exists that both mechanisms are operating simultaneously. More work is necessary, however, to explain the cyclization mechanism of gramicidin $\mathrm{S}$.

Results of binding studies with substrate analogues for gramicidin $S$ synthetase. 1. For the binding of the substrate amino acids of the gramicidin $S$ synthetase on their first activation center - the amino acyl adenylate binding site the $\alpha$-amino group or the imino group in the case of proline is essential. The inhibition constants for the amine substrate analogues which are formed by substituting $\mathrm{H}$ for the carboxyl group of the substrate amino acid, are of the same order of magnitude as their Michaelis constants [66]. N-acyl derivatives of the substrate amino acids are not activated by the multienzyme [67].

2. The carboxyl groups and the side chains of these amino acids do not contribute - or only to a minor fraction - to the binding at the active center. The carboxyl acid substrate analogues in which the $\mathrm{NH}_{2}$ group of the substrate is replaced by $\mathrm{H}$, are not activated by the synthetase [66]. They only show slight or no inhibition of the ATP-PPi exchange in the presence of the corresponding substrate amino acid [66]. The hydrocinnamic acid, the carboxyl acid analogue of phenylalanine, inhibits the light enzyme - but not in a competitive fashion - which means that it most likely does not bind at the reaction center [60]. The esters of the substrate amino acids are activated by the gramicidin $S$ synthetases and catalyze gramicidin $S$ biosynthesis [67]. 
3. The amino acyl adenylate binding site of $\mathrm{L}$-ornithine is characterized by a relatively high substrate variability [67]. When the side chain of L-ornithine is elongated by one $\mathrm{CH}_{2}$ group (lysine), the derivatives are activated by the enzyme and utilized for the biosynthesis of gramicidin S. Analogous results are obtained when the $\delta$-amino group is derivatized by relatively large substituents like e. g. the guanidino group (arginine) or the t-butyloxycarbonyl or trifluoro acetyl group. It is especially interesting that $\mathrm{N}-\delta$-t-butyloxy-carbonyl-L-ornithine with its hydrophobic substituent is bound to the multienzyme about 10-times more tightly than Larginine or $\mathrm{N}-\delta$-trifluoro acetyl-L-ornithine, which contain polar groups at the corresponding position of the molecule. These results indicate that there is a hydrophobic region close to the $\delta$-amino group of the ornithine bound at the reaction center and that this region is available to substituents of the $\delta$-amino group.

Detailed kinetic analyses by ALTMANN et al. [68] established a random binding of the subtrates $\mathrm{Mg} \mathrm{ATP}{ }^{2}$ - and amino acid to the binding site of valine and leucine on the gramicidin $\mathrm{S}$ synthease 2. At high leucine concentrations $(>1 \mathrm{mM})$ the reaction rate of leucine activation increased. These observations were kinetically interpreted by the existence of a second binding site for leucine, which is possibly identical with the binding site for valine on the enzyme. In the absence of valine it was possible to synthesize a peptide of the sequence(D-Phe-Pro-Leu-Orn-Leu) $)_{2}$ [81].

\section{Preparative biosynthesis of peptides}

The production of antibiotics and enzymes and the transformation of substances by cell cultures do not require knowledge of the molecular mechanism. In vitro systems, in which cell extracts and purified macromolecules are used, are easier to investigate and therefore also easier to manipulate. The substitution e. g. of an amino acid in a peptide chain can be achieved without side products because all substrates are controlled.

Peptide synthesing systems may combine amino acids to peptides with the aid of ATP in a one-step process according to the following schemes [35]: $1 \mathrm{nAA}+(\mathrm{n}) \mathrm{ATP} \rightarrow \mathrm{AA}_{\mathrm{n}}+(\mathrm{n}) \mathrm{AMP}+$ (n) $\mathrm{PPi}$

$2 \mathrm{nAA}+(\mathrm{n}-1) \mathrm{ATP} \rightarrow \mathrm{AA}_{\mathrm{n}}+(\mathrm{n}-1) \mathrm{ADP}$ $+(\mathrm{n}-1) \mathrm{Pi}$

The activation of the carboxyl group to an active ester occurs by cleavage of the $\alpha$ - or $\beta$-phospho bond of ATP. The amino groups are protected by binding in a non-covalent fashion at the surface of the protein during the reaction. On a laboratory scale, peptides like glutathion, gramicidin S, tyrocidine, bacitracin, alamethicin are synthesized in enzyme systems free of nucleic acid. In ribosomal systems which use mRNA as matrix, defined proteins can be produced as e.g. thyroglobulin [80] with a molecular weight of 330.000 . The matrix can be isolated and enzymatically copied via DNA, transcribed from isolated genes or chemically synthesized. The absolute yield of all protein biosynthesis processes - tested in vitro - is relatively low, however, because a ribosomal system consists of over 150 components with distinct stabilities. 
Systems which have been tested on a laboratory scale are:

1. relatively unspecific elongation reactions of proteases [35],

2. the synthesis of glutathione on immobilized enzymes [79],

3. the synthesis of gramicidin $S$ with solubilized enzymes.

The last system which represents a special type of multienzyme was investigated most thoroughly.

The preparative formation of gramicidin $\mathrm{S}$ by gramicidin $\mathrm{S}$ synthetase was examined by WANG at M.I.T. [69] during the last years. Up to $100 \mathrm{mg}$ pro- duct/h could be obtained in a 11 -reactor with a soluble enzyme complex according to following equation:

$2 \mathrm{~L}-\mathrm{Phe}+2 \mathrm{~L}-\mathrm{Pro}+2 \mathrm{~L}-\mathrm{Val}+2 \mathrm{~L}-$

Orn +2 L-Leu + 10 ATP

$\rightarrow$ Cyclo(D-Phe-L-Pro-L-Val-L-OrnL-Leu $)_{2}$

$+10 \mathrm{AMP}+10 \mathrm{PPi}$

The utilized ATP can be regenerated by a system of adenylate kinase and acetate kinase [70]. A reaction scheme of the gramicidin $\mathrm{S}$ synthease is given in Fig. 10.

This shows clearly that the peptide synthesis proceeds on an assembly line
GS-SYNTHETASE

1 MG: 100000

2. MG: 280000

Fig. 10. Illustration of reaction sequence leading to gramicidin S. Formation of thioesters occurs at reaction centers (1), (4), (5), (6), (7). The starter amino acid L-Phe $(F)$ is epimerized to D-Phe $(F)$ and transferred to an unknown acceptor (3) on the multienzyme 2. The activated intermediates are transported by 4'-phosphopantetheine in successive transthiolation and transpeptidation reactions. The cyclization reaction (8) occurs by head-to-tail condensation of two pentapeptides.
Abbreviations used are:

L-Phe : F

L-Pro : P

L-Val : V

L-Orn : O

D-Phe : $\bar{F}$

C : cyclo

$*$ : activated intermediate 
without free intermediates. Only the endproduct becomes soluble by release from the enzyme surface. The work with the isolated enzyme systems allows defined substitutions which are either impossible in vivo or which give product mixtures difficult to separate.

The possibilities of the enzyme system as catalyst are not yet exhausted. At the moment the utilization of peptides as a substrate are under investigation [72]. The use of suitable acceptors could allow the synthesis of linear sequences.

The main problems are

1. the stabilization and

2. the required interaction of several multienzymes in the peptide synthesis.

The stabilization of the enzyme systems against protease degradation, oxidation and denaturation has been discussed by Whitesides [70].

In the case of gramicidin S synthetase it was not possible to maintain the activity for longer than 10 hours at $37^{\circ}$ C. In these experiments, protease inhibitors like phenylmethyl sulfonylfluoride were added, oxygen was excluded and foam formation was avoided [70, 73].

To be competitive with the fermentation process in the production of gramicidin $S$, the enzyme system should have a half life of about 30 days at $37^{\circ} \mathrm{C}$ [69]. A solution to this problem might be provided by chemical modification and immobilization. Both are mainly empirical processes at the present time. The immobilization of whole cells of Bacillus brevis for synthesis of gramicidin $\mathrm{S}$ is highly problematic because the product is surface-active and shows a high affinity for the cell membrane. The immobilization of the enzyme system by adsorption or absorption, e.g. on DEAE cellulose prevents the necessary mutual action of the two multienzymes. Alternative possibilities could be the immobilization of only one multienzyme, the covalent coupling of the two multienzymes or simply the enclosure of both multienzymes into a matrix. The latter procedure seems to be favorable because a high local concentration of both enzymes will be achived and therefore a maximal reaction rate is possible. The specific activity of the enzyme preparation is concentration dependent $[74,75]$ and the measured reaction rate can be interpreted in terms of reciprocal action of the two enzymes (complex formation, transfer reaction, dissociation [76]).

Since the peptide synthesizing multienzyme systems described in the past (gramicidin $S$, tyrocidine, bacitracin, linear gramicidin, edeine), show numerous similarities, new preparative possibilities might emerge after the problem of stabilization has been solved.

\section{Acknowledgements}

The author wishes to thank the Drs. E. Pistorius, B. Vennesland, H. Koischwitz, J. VAter, U. Keller and J. Salnikow for their cooperation in preparing this manuscript.

The work mentioned in this article that originated in the author's laboratory was supported by grant KI 148/13 from the Deutsche Forschungsgemeinschaft and BMFT PTB 8013.

\section{References}

1. Berdy, J.: Adv. Appl. Microbiol. 18, 309 (1974).

2. Haavik, H. J.: J. Gener. Microbiol. 96, 393 (1976). 
3. Haavik, H. J. and $\varnothing$. Frøyshov: Nature 254, 79 (1975).

4. v. Hippel, P. H. and J. D. McGhee: Ann. Rev. Biochem. 41, 231 (1972).

5. Sarkar, N. and A. Paulus: Nature New Biol. 239, 228 (1972).

6. Schazschneider, B., H. Ristow and $H$. Kleinkauf: Nature 245, 757 (1974).

7. Ristow, H., B. Schazschneider, K. Bauer and H. Kleinkauf: Biochim. Biophys. Acta 390, 246 (1975a).

8. Ristow, H., B. Schazschneider and H. Kleinkauf: Biochem. Biophys. Res. Commun. 63, 1085 (1975b).

9. Paulus, H. and N. Sarkar: In Nierlich, D. P., Rutter, W. J. and Fox, C. F. (ed.) Molecular Mechanisms in the Control of Gene Expression, Vol. 5, p. 177 (1976).

10. Sarkar, N., D. Langley and H. Paulus: Proc. Natl. Acad. Sci. USA 74, 1478 (1977).

11. Paulus, H.: In D. Gottlieb and P. D. Shaw (ed.) Antibiotics, Vol. 2, p. 254, Berlin 1967, Springer-Verlag.

12. Schaeffer, P., H. Jonesco, A. Ryter and G. Balassa: Colloq. Int. C. N. R. S. 124, 553 (1963).

13. Demain, A. L.: Ann. N. Y. Acad. Sci. 235, 601 (1974).

14. Lee, S. G., V. Littau and F. Lipmann: J. Cell. Biol. 66, 233 (1975).

15. Zharikova, G. G., N. S. Egorov and S. Markelova: 1st Intersectional Congr. Internat. Assoc. Microbiol. Abstr. 1974.

16. Lobareva, G. S., G. G. Zharikova and V. V. Mesyanzhinov: Dokl. Akad. Nauk. SSR 236, 1485 (1977).

17. Schazschneider, B.: pers. communication.

18. Demain, A. L., J. M. Piret, T. E. Friebel, E. J. Vandame and C. C. Matteo: In D. Schlessinger (ed.) Microbiology p. 437, Washington D. C., 1976, Amer. Soc. Microbiol.

19. Kambe, M., Y. Imae and K. Kurahashi: J. Biochem. 75, 481 (1974).

20. Haavik, H. J. and S. Thomassen: J. Gen. Microbiol. 76, 451 (1973).

21. Bu'Lock, J. D.: Adv. Appl. Microbiol. 3, 293 (1961).

22. Demain, A. L.: Lloydia 31, 395 (1968).

23. Audhya, T. K. and D. W. Russel: J. Gen. Microbiol. 86, 327 (1975).
24. Saltero, F. V. and M. J. Johnson: Appl. Microbiol. 1, 52 (1953).

25. Grisebach, H.: Planta Med. 232 Suppl. (1975).

26. Mohr, H.: Dissertation, TU Berlin, 1977.

27. Gallo M. and E. Katz: J. Bacteriol. 109, 659 (1972).

28. Williams, W. K. and E. Katz: Antimicrob. Agents Chemother. 11, 281 (1977).

29. Vandamme, E. J. and A. L. Demain: Prog. Ind. Microbiol. 17, 51 (1976).

30. Haavik, H. J.: J. Gen. Microbiol 81, 383 (1974).

31. Eiser, H. M. and W. C. McFarlane: Canad. J. Res. 26, 164 (1948).

32. Mach, B: Cold Spring Harbor Symp. Quant. Biol. 28, 263 (1963).

33. Tomino, S. and K. Kurahashi: Biochem. Biophys. Res. Commun. 17, 288 (1964).

34. Eikholm, T. S., J. Jonsen, S. Laland and T. Refsvik: Biochim. Biophys. Acta 80, 648 (1964).

35. Kleinkauf, H. and H. Koischwitz: In F. E. Hahn (ed.) Progress in Molecular and Subcellular Biology, Vol. 6, 59, Heidelberg 1978, Springer-Verlag

36. Katz, E. and A. L. Demain: Bacteriol. Reviews 41, 449 (1977).

37. Kurahashi, K.: In E. Snell (ed.) Annual Review of Biochemistry, Vol. 43, p. 445, Calif. 1974, Ann. Reviews. Inc.

38. Laland, S. G. and T. Zimmer: In P. N. Campbell and Dickens, F. (ed.), Essays in Biochemistry, Vol. 9, p. 31, London (1973), Biochem. Soc. Academic Press.

39. Lipmann, F.: Science 173, 875 (1971).

40. Saito, Y., S. Otani and S. Otani: In F. F. Nord (ed.) Advances in Enzymology, Vol. 33, p. 337, New York 1970, Interscience Publ.

41. Mohr, H. and H. Kleinkauf: Biochim. Biophys. Acta, in press.

42. Zharikova, G. G., A. P. Zarubina, D. M. Kherat, S. P. Myaskovskaya, V. N. Maksimov: Antibiol. J. k. h. Produtsenty, p. 163, Moscow: Nauka 1975.

43. Kleinkauf, H. and W. Gevers: Cold Spring Harbor Symp. Quant. Biol. 34, 805 (1969).

44. Roskoski, R. Jr., W. Gevers, H. Kleinkauf and F. Lipmann: Biochemistry 9, 4839 (1970). 
45. Gevers, W., H. Kleinkauf and F. Lipmann: Proc. Natl. Acad. Sci. USA 60, 269 (1968).

46. Gevers, W., H. Kleinkauf and F. Lipmann: Proc. Natl. Acad. Sci. USA 63, 1335 (1969).

47. Gilhus-Moe, C. C., T. Kristensen, J. E. Bredesen, T. L. Zimmer and S. G. Laland: FEBS Lett. 7, 287 (1970).

48. Kleinkauf, H., W. Gevers, R. Jr. Roskoski and F. Lipmann: Biochem. Biophys. Res. Commun. 41, 1218 (1970).

49. Kleinkauf, $H$. and $H$. Koischwitz: In D. Richter (ed.) Lipmann-Symposium: Energy, Biosynthesis and Regulation in Molecular Biology, P. 336, New York 1974, W. d. Gruyter-Verlag.

50. Kleinkauf, H., R. Jr. Roskoski and F. Lipmann: Proc. Natl. Acad. Sci. USA 68, 2069 (1971).

51. Roskoski, R. Jr., G. Ryan, H. Kleinkauf, W. Gevers and F. Lipmann: Arch. Biochem. Biophys. 143, 485 (1971).

52. Pass, L., T. Zimmer and S. G. Laland: Europ. J. Biochem. 40, 43 (1973).

53. Vater, J. and H. Kleinkauf: 12th FEBS Meeting, Dresden, 1978.

54. Wecke, J., P. Giesbrecht and H. Koischwitz: unpublished.

55. Koischwitz, H.: Dissertation, TU Berlin, 1978.

56. Lee, S. G. and F. Lipmann: Proc. Natl. Acad. Sci. USA 74, 2343 (1977).

57. Lee, S. G. and F. Lipmann: Proc. Natl. Acad. Sci. USA 71, 607 (1974).

58. Lipmann, F.: Acc. Chem. Res.: 6, 361 (1973).

59. Akers, H. A., S. G. Less and F. Lipmann: Biochemistry 16, 5722 (1977).

60. Vater, J. and H. Kleinkauf: Biochim. Biophys. Acta 429, 1062 (1976).

61. Koischwitz, H. and H. Kleinkauf: Biochim. Biophys. Acta 429, 1052 (1976).

62. Christiansen, C., A. Aarstadt, T. L. Zimmer and S. G. Laland: FEBS Lett. 81, 121 (1977).

63. Lipmann, F., W. Gevers, H. Kleinkauf and R. Roskoski Jr.: Adv. Enzymol. 35, 1 (1971).

64. Stoll, E., Ø. Frøyshov, H. Holm, T.-L.
Zimmer and S. G. Laland: FEBS Lett. 11, 348 (1970).

65. Saxholm, H., T.-L. Zimmer and S. G. Laland: Eur. J. Biochem. 30, 138 (1972).

66. Vater, J.: 10. Intern. Congress of Biochemistry, Hamburg 1976 Abstr. 16-7-252.

67. Vater, J. and H. Kleinkauf: Acta Microbiol. Acad. Syi. Hung. 22, 419 (1975).

68. Altmann, M., H. Koischwitz and H. Kleinkauf: 12th FEBS Meeting, Dresden, 1978.

69. Wang, D. J. C., J. G. Stramondo, R. Fleischaker: In N. Sharon, E. Bohak/eds.), Biotechnological Applications of Proteins and Enzymes. New York - London 1977, Academic Press.

70. Witesides, G. M.: In J. B. Jones, C. J. Sih, D. Perlman (eds.) Large-Scale Organic Synthesis Using Cell-Free Enzymes, p. 901, 1976, Wiley.

71. Koischwitz, H.: 5th Int. Fermentation Symp. Berlin 1976, Abstract 12-14

72. v. Dungen, A., J. Vater, and H. Kleinkauf: Eur. J. Biochem. 66, 623 (1976).

73. Friebel, T. E. and A. L. Demain: J. Bacteriol. 130, 1010 (1977).

74. Tzeng, C. H., K. D. Thraser, J. P. Montgomery, B. U. Hamilton and D. J. C. Wang: Biotechn. Bioeng. 17, 143 (1975).

75. Koischwitz, H. and H. Kleinkauf: Biochim. Biophys. Acta 429, 1041 (1976).

76. Wang, D. J. C. and B. U. Hamilton: Biotechn. Bioeng. 19, 1225 (1977).

77. Chan, W. W.-C.: Biochemistry 7, 4251 (1968).

78. Engeser, H., F. Wieland and F. Lynen: FEBS Lett. 82, 139 (1977).

79. Miwa, N.: (Kanebo, Ltd.), Japan Kokai 76, 144, 789 (1976)

80. Chebath, J., O. Chabaud, A. Becarevic, G. Cartouzou and S. Lissitzky: J. Biochem. 77, 243 (1977).

81. Altmann, M., H. Koischwitz, J. Salnikow and H. Kleinkauf: FEBS Lett. 93, 247 (1978).

Address: Prof. Dr. H. Kleinkauf Max Volmer-Institut für Physikalische Chemie und Molekularbiologie, Abtl. Biochemie Franklinstraße 29, D-1000 Berlin 10 